\title{
Interactive comment on "Reassessing long-term drought risk and societal impacts in Shenyang, Liaoning province, Northeast China (CE 1200-2015)" by LingYun Tang et al.
}

\section{Anonymous Referee \#1}

Received and published: 24 October 2019

The authors present an interesting paper that reassesses long term drought and societal impacts in Shenyang, Liaoning province, Northeast China (1200-2015). My suggestions mainly concern the quality and coherence of the writing and some presentation issues. The language in the paper could be tightened significantly, which would make it easier for the reader to understand. The suggestions are not exhaustive, and I have made some other suggestions that I feel will improve the manuscript further.

\section{General Suggestions}

The placement of in text citations in certain places makes it difficult to read, suggest placing them at the end of the sentence (Lines 75-81 for example). Also, the writing 
could be generally improved across the manuscript. Suggest re-reading and edit the text to improve the flow of the writing in places (for example; lines 69-72 are difficult to read and could be written much clearer).

Specific suggestions

Line 26: Add "common era for the reader who does not know what CE means. Or omit CE or rephrase to" the year 2000" same for line 28,33.

Line 49: Should not be "an" change to a.

Line 52 Suggest changing sentence to read; "there is no universal definition for drought with a variety of definitions used around the world", with many focusing on a deficiency in precipitation over a period of time"

Lines 56-60 Suggest re wording this paragraph, it is a bit repetitive and can be tightened up somewhat to be more concise.

Line 58,59 and 62 I don't like the use of e.g. too much try using "for example" or "such as".

Line 63, 64: Define the 5 types of droughts for the reader, they may not be familiar with them.

Line 68 should be double quotes for a direct quote. "drought means various things to various people, depending on specific interest"

Line 92 no full stop after and

Line 99 What is meant by micro, light, mid, heavy and extreme drought?

Line 104 Is rainfall and snow depth only recorded in 1736 or from 1736 ?

Line 109 Suggest changing "but felt acutely in China" to "but drought poses a serious threat to food security, environmental ecology, urban and rural water supply in China" 
Line 127 use million not $\mathrm{M}$, same elsewhere

Line 194-196 Are these station ID's or collections? please clarify Also it is unclear CPD whether you are using the other variables besides precipitation in your analysis of drought? If not, why present please clarify.

Line 238-271 This paragraph is difficult to follow and requires re-writing. It is unclear if you are using individual station data or a mean composite of all stations. It is also comment unclear which datasets you are referring to, you need to name your datasets clearly at the onset and be consistent throughout. If you have 60 sites with precipitation records why not perform some homogeneity check on them using pair wise detection? This section needs a some more work to make it much clearer and more coherent for the reader.

Line 203 (1960-?) to date?

Line 207 Change to "is used in this study"

Line 227 Belonged not belonging.

Line 290 if you have temperature records have you considered using SPEI to include ET?

Line 293 Are you using the China $<.50$ as drought onset or the widely used Mc Kee and WMO classifications? It is unclear.

Line 295 A useful paper to look at is Noone et al. 2017 (https://rmets.onlinelibrary.wiley.com/doi/10.1002/joc.4999) whose 250-drought analysis for Ireland identify and clearly present drought duration, severity, timing in long precipitation records and verify drought periods with documentary evidence.

Line 303 Why use SPI-1 and not SPI-3 for identifying agricultural drought?

Line 457-458 Which SPI accumulation are these values (SPI-1, 6 or 12)? Same elsewhere e.g. lines 493-499, please clarify the SPI accumulation.

Printer-friendly version

Discussion paper 
Line 465 Change to " 5000,000 people died"

Line 468 Change $3 m$ to 3 million people

Line 473 Similar accounts of praying for rain can be found in other parts of the world see Murphy et al. 2016 (https://rmets.onlinelibrary.wiley.com/doi/full/10.1002/wea.2904)

Line 476-482 Suggest breaking up this sentence it is very long.

Interactive

comment

Line 509 Why do you think SPI has a significant correlation with ENSO3.4 summer and autumn? Give some explanation to the reader.

Line 534 Could the lack of documentary evidence to support the identification of drought in the observations be issues with the data itself? Have you explored this possibility? See Murphy et al. 2019 (https://rmets.onlinelibrary.wiley.com/doi/full/10.1002/joc.6208)

Figure 1 suggest filling the colour of the Liaoning province on the map of China and remove the dotted guidelines.

Figure 5 add in dotted lines at the value of onset of drought, moderate, severe, and extreme drought to plots, you will need to change the axis values.

Figure $6 \mathrm{It}$ is difficult to interpret this plot, suggest a better description in the figure caption or redo plots to make clearer. There is a lot going on in these plots and l'm not sure that they should be combined as they are for different periods. Please rethink how to display the results.

Interactive comment on Clim. Past Discuss., https://doi.org/10.5194/cp-2019-106, 2019. 